\title{
METHODOLOGIES IN IDENTIFICATION, ANALYSIS, AND MEASUREMENT OF VISUAL POLLUTION: THE CASE STUDY OF INTRAMUROS
}

\begin{abstract}
The problem of visual pollution in the Philippines has been increasingly evident, and people are becoming aware of it. But to create effective solutions, a deep understanding of the problem should first be established. This paper was aimed to identify, analyze, and measure the visual pollution present in Intramuros, a heritage city in the Philippines that encapsulates the Philippine colonial architecture in the 1890s. The site is known for its preservation of its city image but also modern landscape changes. To achieve the goal, the application of the Indirect and Direct Method of Landscape Evaluation was executed. These methods led to two results: (1) the identification of components - which are landscape attributes and indicators, that make up a visual landscape; and (2) the understanding of how it is perceived by the observer through a survey and interviews, which are quantified by ratings. To further understand the relationship of indicators and ratings with each other, a series of correlational studies was done. This resulted to the establishment of Disturbance, Stewardship, and Image Rating as the primary descriptors of visual pollution. A weighted average formula was then established, which quantified the visual pollution of Intramuros through indicator values and response ratings. It was concluded that visual pollution in Intramuros, through research-based methodology, can be identified, analyzed, and measured. Specific viewpoints in the district were identified as unacceptably visually-polluted. Magallanes St. cor. Victoria St. in Intramuros had the highest VP Score at -4.886 . Elements that contributed to visual pollution were also identified.
\end{abstract}

Keywords: green open space, Jakarta, Singapore, planning

Accepted: 05 March 2021

\section{INTRODUCTION}

Humans, through vision, constantly communicate with the environment. Through this constant process of visual communication, humans develop and redevelop a mental map wherein information, memories, experiences, ideas, and feelings are stored. This collection of information defines the city to a single person in a community. The similarities among the many collections from the whole community in a city is what Lynch (1960) referred to as the "image of the city." He proposed that this large collection of information is the perception of the community towards the city. Moles (2016) says that this image dictates the community's way of life, making impacts in the people's daily decision-making. As the community moves about the environment and gathers new information, the image is continuously revised - creating a two-way constant communication between the community and the environment (Lynch, 1960).

Portella (2014); Jana and De (2015) stated that this image can be degraded by visual pollution, which they defined as the elements in or of the landscape that are unattractive and disrupt the ability of the people to enjoy the view/s in the city. Portella (2014) further states that the proliferation of visual pollution can lead to the image of the city's degradation in historic cities, altering its image unrelated to its past.

This phenomenon has become evident in the cities of the Philippines. The rapid urbanization has brought about a proliferation of disjoint elements in the environment in terms of aesthetics and character. This led to a confusing mix of elements from different styles and eras of architecture and design. The Walled City of Intramuros in Manila, known for its preservation of its Philippines colonial architecture dating back to the 1890s, has begun to exhibit this phenomenon through the emergence of various modern elements.

Due to the increasing awareness of the problem, a deeper understanding of the problem should be established. There is a lack of related studies in the Philippines, which is why the identification, analysis, and measurement of visual pollution has not been established. This paper aims to create a deeper definition of visual pollution and establish a methodology that will identify, analyze, and measure visual pollution in Intramuros. Due to the travel restrictions implemented in the country due to the COVID19 pandemic, the 360 panorama photos used in this study were retrieved online from Google Maps.

\section{METHODOLOGY}

According to Portella (2014), visual pollution has two aspects: the (1) non-affective, which pertains to the tangible, concrete objects or elements of the visual landscape; and the (2) affective, which pertains to the intangible elements such as pleasantness, stressfulness, and security. The non-affective aspect relates to Lynch's Image of the City (1960) wherein the construction of the environment directly affects the visual landscape. The affective aspect is explained clearly by Berlyne's Theory of 
Aesthetics as stated by Ode et al. (2010), wherein a stimulus is assessed through the survey of subjects on whether they like the stimulus, and predicts that subjects are happiest with intermediate levels of stimulation and uncertainty. To properly assess the two aspects, a different method was applied for each aspect (Arriaza et al., 2004; Chmielewski et al., 2016). Figure 1 presents the methodological diagram of the study.

\section{Viewpoint Selection Process}

A selection process was first established in order to delimit and create a representative and diverse group of viewpoints to be assessed. The grid-sampling method done by de la Fuente et al. (2006) was adopted as the selection process. Gridline spacing was reduced from $5 \mathrm{~km}$ to $200 \mathrm{~m}$ in consideration of the maximum viewshed length possible in Intramuros. It is important to note that

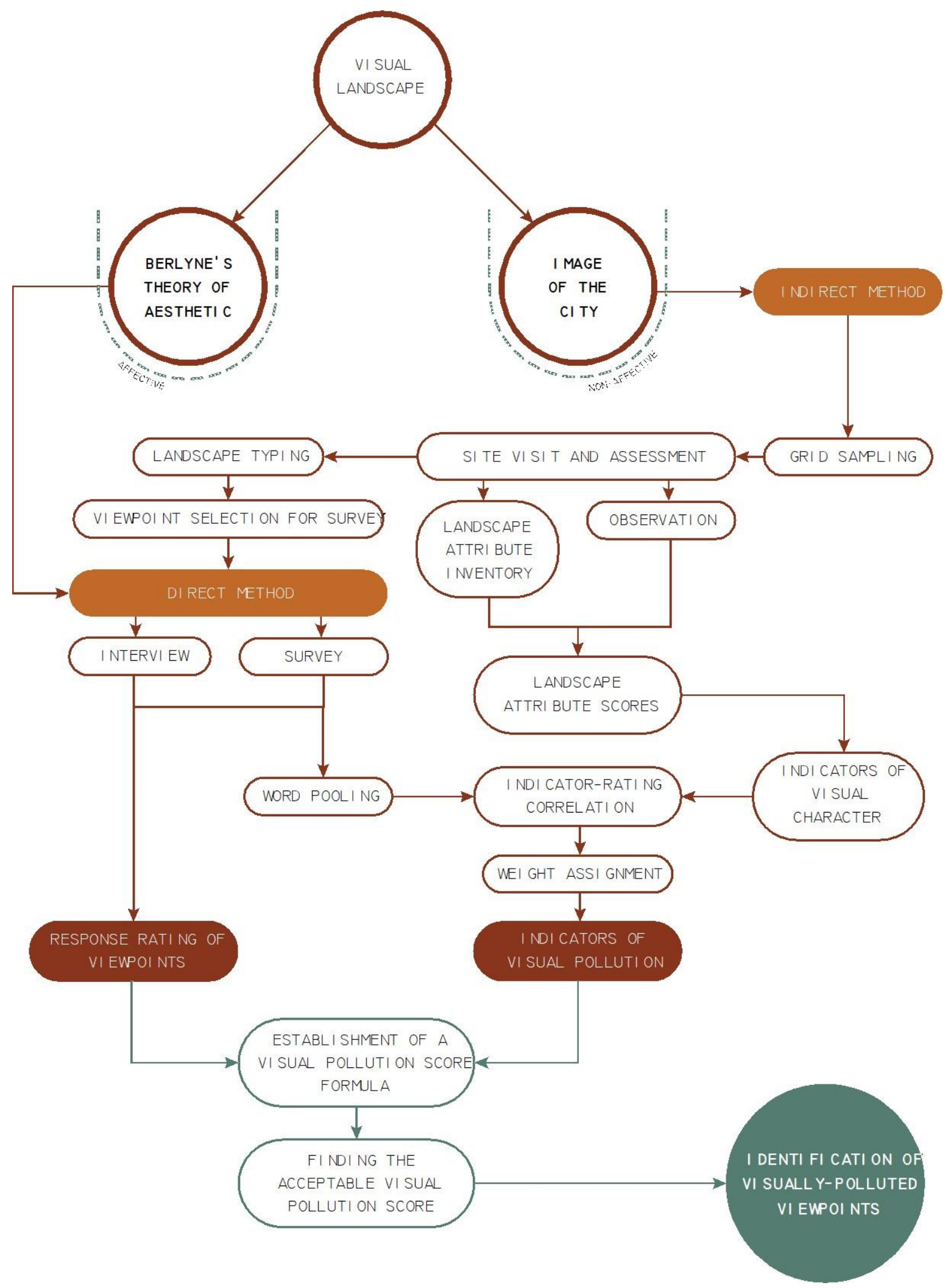

Figure 1. Methodological Diagram of the Study 
only viewpoints belonging to the public environment were considered. Grid intersections that fell on private domain were substituted by the nearest viewpoint of the public environment. The 360 panorama photos of each selected viewpoint were extracted from Google Maps.

\section{Indirect Method - Landscape Attribute Inventory}

The Landscape Attribute Inventory focused on breaking down the visual landscape into smaller, measureable components in order to create a quantitative estimate of the whole visual landscape. Ode et al. (2008) defined various indicators, and the attributes that makes up an indicator, that capture the landscape visual character. The study factored in the indicators Complexity, Disturbance, Imageability, Naturalness, Visual Scale, and Stewardship. This required the eight attributes to be measured in the 360 panorama photos. Table 1 shows the criteria and attributes included for each indicator. Attributes 1, 2, 8, and 9 were measured by manual observation. Attributes 3, 4, 5, 6, and 7 were measured by calculating the percentage of the attribute's presence in number of pixels in the 360 landscape photo. The pixel count was determined by looking at the photo metadata through the Histogram tab in Adobe Photoshop CC ver. 14. Figure 2 presents the screen capture showing the Histogram tab of a sample landscape photo. In the Histogram tab, the "Pixels" denote the number of pixels of the entire image. Figure 3 presents the screen capture showing the histogram tab when HEv attribute is selected in the image. Computations were done in Microsoft Excel 2016. The result is the Landscape Attribute Inventory, a consolidated tabulation of indicator and attribute scores per viewpoint.

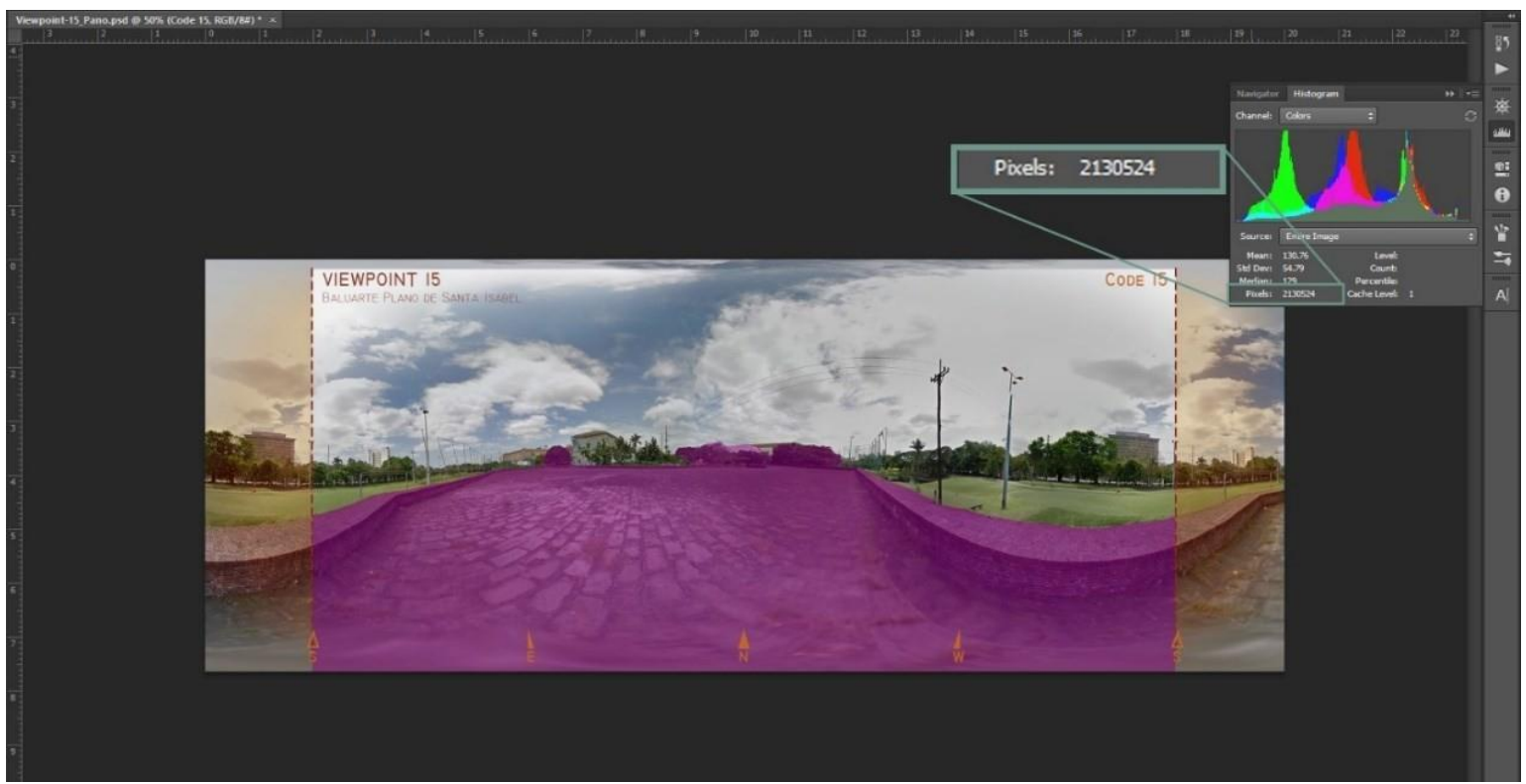

Figure 2. Screen capture of Adobe Photoshop CC Showing Pixel Count of a Sample Landscape photo through Histogram tab

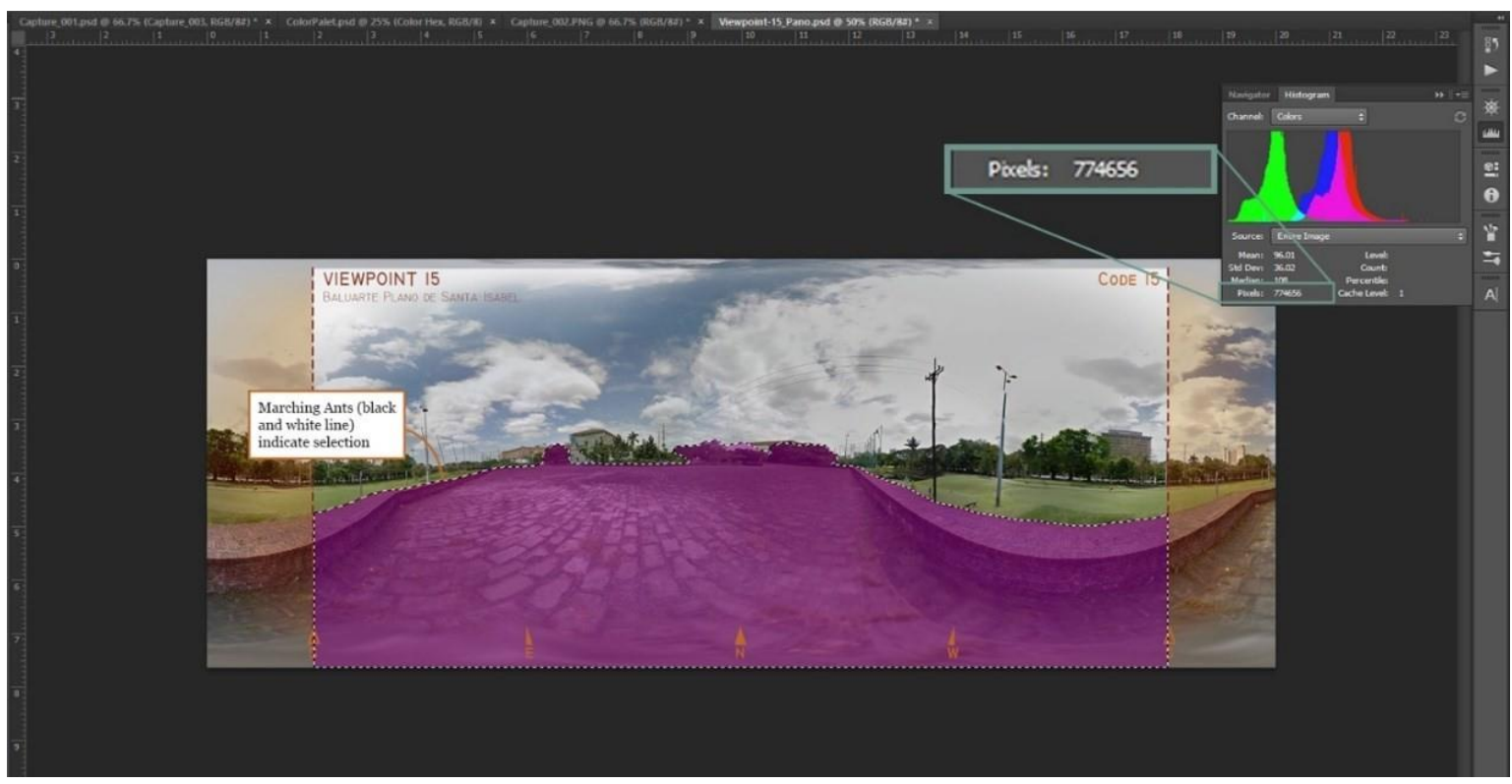

Figure 3. Screen capture of Adobe Photoshop CC showing pixel count of selected attribute (HEv) of the same landscape photo through Histogram tab 
Table 1. Criteria for Each Indicator and Attribute

\begin{tabular}{|c|c|}
\hline Indicators & Attributes and their Criteria \\
\hline Complexity & $\begin{array}{ll}\text { (1) Number of Elements in view (NEv) - } & \text { (2) Land Cover in view (LCv) - number of } \\
\text { number of elements seen in the landscape photo; } & \text { identifiableland coverinview (such as built-up } \\
\text { similar elements are grouped into one (such as } & \text { land, vegetation, water body, etc.) } \\
\text { a row of lamp posts) } & \end{array}$ \\
\hline Disturbance & $\begin{array}{l}\text { (3) Disturbing Elements in view (DEv) - elements that do not conform with the prescribed } \\
\text { architectural style for Intramuros and/or do not correspond with the identity of its surroundings }\end{array}$ \\
\hline $\begin{array}{l}\text { Imageability } \\
\text { (I. score = } \\
\text { average of } \\
\text { SUIFv\%, } \\
\text { HEv\%, and } \\
\text { Wv\%) }\end{array}$ & 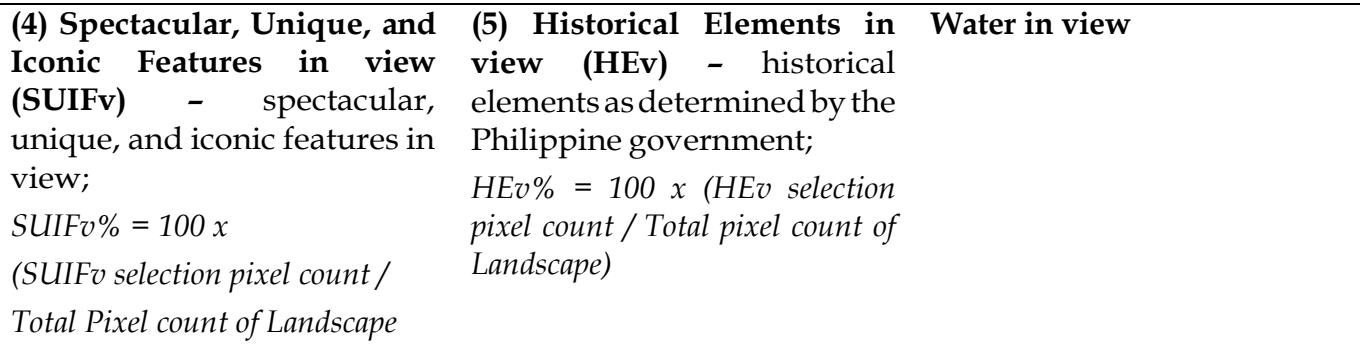 \\
\hline $\begin{array}{l}\text { Naturalness } \\
\text { (N. score }=\text { Vv } \\
+ \text { Wv / Total } \\
\text { Pixel Count of } \\
\text { Landscape) }\end{array}$ & $\begin{array}{l}\text { (7) Vegetation in view }(\mathbf{V v})- \\
\text { vegetation/flora in view; } V v=V v \text { selection } \\
\text { pixel count }\end{array}$ \\
\hline Visual Scale & $\begin{array}{l}\text { (8) Long Viewsheds in view (LVv) - number of } 90^{\circ} \text { viewsheds that extend up to } 100 \text { meters; } \\
\text { measured through observation }\end{array}$ \\
\hline Stewardship & $\begin{array}{l}\text { (9) Perceived Maintenance in view (PMv) - perceived maintenance of the landscape measured } \\
\text { through observation; tallied by a scoring system; maximum of } 100 \text { pts } \\
\text { Criteria: } \\
\text { a. ( } 50 \text { pts) Areas receive regularly-scheduled and organized softscape and hardscape } \\
\text { maintenance and care } \\
\text { b. ( } 50 \text { pts) Low visual clutter content, any type of waste is not seen in view } \\
\text { c. ( } 30 \text { pts) Areas receive unorganized softscape and hardscape maintenance such as watering of } \\
\text { plants, sweeping, and repair } \\
\text { d. ( } 30 \text { pts) Moderate visual clutter content, few wastes are seen } \\
\text { e. }(0 \mathrm{pt}) \text { Areas do not receive maintenance aside from occasional sweeping } \\
\text { f. ( } 0 \text { pt) High visual clutter content, waste products are evident and uncontrolled in thelandscape }\end{array}$ \\
\hline
\end{tabular}

\section{Landscape Coding}

Viewpoints were grouped by landscape codes in order to further narrow the pool of photos utilized for the Direct Method. The viewpoints were classified by the researcher into categories in each indicator. The parameters are presented in Table 2. A Landscape Code is a group of viewpoints with similar indicator-based descriptor, which is the merged category codes of a viewpoint divided by dashes (ex. S-LD-HI-HI-MVO-HM).

Table 2. Landscape Coding Parameters table used as the criteria for categorization for each indicator

\section{Direct Method - Survey and Interview}

The direct method took into account the variable of personal taste. An online survey and interview were done for this method. The survey was aimed to assess how the landscape codes were classified in the pair descriptors (Green, 1999) "beautiful-ugly" and "interesting-boring", and if they fit their image of Intramuros. Each landscape code was represented by one 360 panorama photo of its corresponding viewpoint. The viewpoint with the least deviation from the median score per indicator categories

\begin{tabular}{|c|c|c|c|}
\hline Complexity & $\mathbf{S}$ (Simple) - NEv $<13, \mathrm{LCV}<2$ & C (Complex) - & $\mathrm{NEv}>13, \mathrm{LCv}>2$ \\
\hline Disturbance & $\begin{array}{l}\text { NLD (None to Lightly } \\
\text { Disturbed) }- \text { DEv } \%<10 \%\end{array}$ & $\begin{array}{l}\text { MD(Moderately Disturbed) - } \\
10 \%<\text { DEv } \%>30 \%\end{array}$ & $\begin{array}{l}\text { ED (Extremely Disturbed) } \\
- \\
\text { DEv } \%>30 \%\end{array}$ \\
\hline Imageability & $\begin{array}{l}\text { LI (Lowly Imageable) - I. } \\
\text { Score > 30\% }\end{array}$ & $\begin{array}{l}\text { MI (Moderately Imageable) - } \\
30 \%<\text { I. Score }>60 \%\end{array}$ & $\begin{array}{l}\text { HI (Highly Imageable) - I. } \\
\text { Score }>60 \%\end{array}$ \\
\hline Naturalness & $\begin{array}{l}\text { LN (Lowly Natural) - N. Score } \\
>30 \%\end{array}$ & $\begin{array}{l}\text { MN (Moderately Natural) - } \\
30 \%<\text { N. Score }>60 \%\end{array}$ & $\begin{array}{l}\text { HN (Highly Natural) - N. } \\
\text { Score }>60 \%\end{array}$ \\
\hline Visual Scale & $\begin{array}{l}\text { LVO (Lowly Visually Open) - } \\
\mathrm{LVV}<2\end{array}$ & $\begin{array}{l}\text { MVO (Moderately Visually } \\
\text { Open) }-2<\mathrm{LVV}>3\end{array}$ & $\begin{array}{l}\text { HVO (Highly Visually Open) } \\
-L_{V}>4\end{array}$ \\
\hline Stewardship & $\begin{array}{l}\text { NLM (Non to Lightly } \\
\text { Maintained) }-\mathrm{PMv}<50\end{array}$ & $\begin{array}{l}\text { MM (Moderately Maintained) } \\
-50<\text { PMv }>90\end{array}$ & $\begin{array}{l}\text { HM (Highly Maintained) - } \\
\text { PMv > } 90\end{array}$ \\
\hline
\end{tabular}


were chosen to represent their respective codes in the survey (Barroga, 2020c). The opportunity sampling technique was used for this study. The survey gathered 121 responses, wherein 33 came from residents of Manila where Intramuros is located. 31 of the 33 residents and 62 of the 88 non-residents said on the day of the survey that they have visited Intramuros. This resulted to a tabulation of responses. The interview was aimed to gather information from Intramuros Administration Cultural Properties Conservation Division Chief Architect Ramil Tibayan and Urban Planning and Community Development Division Chief Marrietta Allaga to gain insight on visual pollutants that affect the mandated and planned urban design aesthetic of the city. The interview guide (Barroga, 2020b) was derived from Lynch's (1960) and Portella (2014). This resulted to identification of specific indicators, attributes, and elements that have a bigger impact to the characteristics of visual pollution.

\section{RESULTS}

A total of 30 viewpoints were identified in Intramuros using the grid-sampling method. Their corresponding 360 photos were extracted from Google Maps and analyzed through the Indirect Method. Datasets gathered and calculated in this study can be accessed through DOI: 10.5281/zenodo.4014913 (Barroga, 2020a).

\section{Landscape Attribute Inventory}

\section{Landscape Codes}

Through the Landscape Attribute Inventory, the landscape code per viewpoint was determined. Table 4 presents the landscape codes of all viewpoints. Highlighted entries represented their respective codes in the survey.

\section{Tabulation of Responses}

Table 5 presents the tabulation of responses of each landsape code across the three rating areas. Beauty column shows the respondents who answered that the landscape is beautiful. Interest column shows those who answered that the landscape is interesting. Image column shows the responses saying that the landscape is taken in Intramuros.

\section{Interview Results}

An interview was conducted with architect and Intramuros Administration - Cultural Preservation Division Chief Ramil Tibayan, and professor and Intramuros Administration - Urban Planning and Community Development Division Chief Marrietta Allaga. They stated that while the City of Manila exhibits a diverse collection of images and characters, Intramuros has been able to preserve the Philippine colonial architecture of the 1890s. Despite this, they have said that elements such as electric cable wires and posts, mish-mash of materials of informal settlements, and commercial advertisements do not conform to the mandate of Intramuros. Through this, the indicators Disturbance and Stewardship were pointed out as the more evident factors in identifying and measuring visual pollution.

Table 3. Table presents the consolidated scores of attributes of all the viewpoints tallied from the Landscape Attribute Inventory done by the researcher

\begin{tabular}{|c|c|c|c|c|c|c|c|c|c|c|}
\hline Viewpoint & Ev & LCv & DEv\% & SUIFv\% & HEv \% & Wv \% & Wv & Vv & LVv & $\mathbf{P M v}$ \\
\hline 1 & 11 & 2 & 0 & 67.517 & 77.07 & 17.092 & 166489 & 159057 & 3 & 30 \\
\hline 2 & 11 & 2 & 1.435 & 35.549 & 99.884 & 0 & 0 & 985579 & 1 & 100 \\
\hline 3 & 10 & 2 & 10.140 & 0 & 0 & 0 & 0 & 172838 & 1 & 60 \\
\hline 4 & 11 & 1 & 0 & 47.360 & 100 & 0 & 0 & 530324 & 1 & 100 \\
\hline 5 & 20 & 2 & 11.640 & 8.633 & 0 & 0 & 0 & 84896 & 2 & 60 \\
\hline 6 & 12 & 2 & 11.508 & 13.063 & 0 & 0 & 0 & 200303 & 3 & 60 \\
\hline 7 & 13 & 1 & 7.978 & 37.063 & 28.287 & 0 & 0 & 384725 & 2 & 60 \\
\hline 8 & 24 & 1 & 10.639 & 20.594 & 0 & 0 & 0 & 108139 & 3 & 60 \\
\hline 9 & 17 & 1 & 14.382 & 33.874 & 0 & 0 & 0 & 99987 & 2 & 60 \\
\hline 10 & 14 & 2 & 0.015 & 25.843 & 0 & 0 & 0 & 251029 & 3 & 80 \\
\hline 11 & 14 & 2 & 1.383 & 51.601 & 0.338 & 0 & 0 & 822394 & 1 & 80 \\
\hline 12 & 18 & 1 & 12.040 & 59.328 & 0 & 0 & 0 & 106324 & 2 & 30 \\
\hline 13 & 28 & 1 & 20.469 & 1.430 & 0 & 0 & 0 & 319231 & 4 & 0 \\
\hline 14 & 22 & 1 & 14.264 & 11.526 & 0 & 0 & 0 & 55202 & 2 & 60 \\
\hline 15 & 9 & 2 & 1.356 & 97.598 & 81.519 & 0 & 0 & 150128 & 4 & 100 \\
\hline 16 & 8 & 1 & 1.591 & 97.724 & 91.445 & 0 & 0 & 127638 & 4 & 100 \\
\hline 17 & 18 & 1 & 18.950 & 1.829 & 21.234 & 0 & 0 & 4735 & 2 & 60 \\
\hline 18 & 20 & 1 & 14.791 & 22.530 & 0 & 0 & 0 & 263512 & 2 & 0 \\
\hline 19 & 15 & 1 & 6.703 & 89.650 & 29.356 & 0 & 0 & 27251 & 3 & 100 \\
\hline 20 & 11 & 3 & 0 & 96.435 & 74.596 & 1.181 & 11765 & 153659 & 4 & 100 \\
\hline 21 & 12 & 2 & 1.866 & 22.222 & 0.080 & 0 & 0 & 280193 & 2 & 80 \\
\hline 22 & 8 & 1 & 0.055 & 98.896 & 90.480 & 0 & 0 & 25014 & 3 & 100 \\
\hline 23 & 23 & 1 & 18.433 & 0 & 0 & 0 & 0 & 2776 & 2 & 0 \\
\hline 24 & 15 & 1 & 3.882 & 40.224 & 0 & 0 & 0 & 92979 & 2 & 100 \\
\hline 25 & 14 & 3 & 0 & 66.251 & 47.938 & 3.425 & 34469 & 440467 & 3 & 100 \\
\hline 26 & 15 & 2 & 0.369 & 0.028 & 0 & 0 & 0 & 535967 & 2 & 50 \\
\hline 27 & 11 & 3 & 0.251 & 92.607 & 85.392 & 0.133 & 1232 & 56471 & 3 & 100 \\
\hline 28 & 13 & 1 & 0 & 68.990 & 0.384 & 0 & 0 & 1319780 & 0 & 80 \\
\hline 29 & 8 & 2 & 0 & 98.115 & 84.843 & 0 & 0 & 232472 & 4 & 80 \\
\hline 30 & 16 & 2 & 3.062 & 0 & 0 & 0 & 0 & 125802 & 4 & 60 \\
\hline
\end{tabular}


Table 4. Table of Landscape Codes of all viewpoints with corresponding indicator-based descriptors.

\begin{tabular}{|c|c|c|c|c|c|}
\hline $\mathbf{v}$ & Indicator-Based Descriptor & Landscape Code & $\mathbf{v}$ & Indicator-Based Descriptor & Landscape Code \\
\hline 1 & S-NLD-MI-MN-MVO-LM & CODE 14 & 16 & S-NLD-HI-LN-HVO-HM & CODE 9 \\
\hline 2 & S-NLD-MI-HN-LVO-HM & CODE 12 & 17 & C-MD-LI-LN-MVO-MM & CODE 2 \\
\hline 3 & S-MD-LI-MN-LVO-MM & CODE 7 & 18 & C-MD-LI-LN-MVO-NLM & CODE 3 \\
\hline 4 & S-NLD-MI-LN-LVO-HM & CODE 17 & 19 & S-NLD-MI-LN-MVO-HM & CODE 16 \\
\hline 5 & C-MD-LI-LN-MVO-MM & CODE 2 & 20 & C-NLD-MI-LN-HVO-HM & CODE 4 \\
\hline 6 & S- MD-LI-LN-MVO-MM & CODE 8 & 21 & S-NLD-LI-LN-MVO-MM & CODE 22 \\
\hline 7 & S-NLD-LI-LN-MVO-MM & CODE 22 & 22 & S-NLD-HI-LN-MVO-HM & CODE 11 \\
\hline 8 & C-MD-LI-LN-MVO-MM & CODE 2 & 23 & C-MD-LI-LN-MVO-NLM & CODE 3 \\
\hline 9 & C-MD-LI-LN-MVO-MM & CODE 2 & 24 & S-NLD-LI-LN-MVO-HM & CODE 21 \\
\hline 10 & S-NLD-LI-LN-MVO-MM & CODE 22 & 25 & S-NLD-MI-MN-MVO-HM & CODE 13 \\
\hline 11 & S-NLD-LI-MN-LVO-MM & CODE 20 & 26 & S-NLD-LI-MN-MVO-MM & CODE 19 \\
\hline 12 & C-MD-LI-LN-MVO-NLM & CODE 3 & 27 & C-NLD-MI-LN-MVO-HM & CODE 5 \\
\hline 13 & C-MD-LI-LN-HVO-NLM & CODE 1 & 28 & S-NLD-LI-HN-LVO-MM & CODE 18 \\
\hline 14 & C-MD-LI-LN-MVO-MM & CODE 2 & 29 & S-NLD-HI-LN-HVO-MM & CODE 10 \\
\hline 15 & S-NLD-MI-LN-HVO-HM & CODE 15 & 30 & C-NLD-LI-LN-HVO-MM & CODE 6 \\
\hline
\end{tabular}

Table 5. Tabulation of Responses from survey showing Beauty, Interest, and Image ratings.

\begin{tabular}{cccccccc}
\hline Code & Beauty & Interest & Image & Code & Beauty & Interest & Image \\
\hline $\mathbf{1}$ & 11.57 & 26.446 & 24.793 & $\mathbf{1 2}$ & 85.124 & 84.298 & 76.033 \\
$\mathbf{2}$ & 22.314 & 40.496 & 60.331 & $\mathbf{1 3}$ & 84.298 & 84.298 & 91.736 \\
$\mathbf{3}$ & 19.008 & 28.099 & 31.405 & $\mathbf{1 4}$ & 45.455 & 76.033 & 60.331 \\
$\mathbf{4}$ & 80.165 & 85.950 & 97.521 & $\mathbf{1 5}$ & 80.992 & 68.595 & 90.083 \\
$\mathbf{5}$ & 79.339 & 84.298 & 98.347 & $\mathbf{1 6}$ & 66.116 & 77.686 & 94.215 \\
$\mathbf{6}$ & 55.372 & 49.587 & 31.405 & $\mathbf{1 7}$ & 93.388 & 78.512 & 71.901 \\
$\mathbf{7}$ & 20.661 & 29.752 & 32.231 & $\mathbf{1 8}$ & 92.562 & 83.471 & 75.207 \\
$\mathbf{8}$ & 53.719 & 71.074 & 23.140 & $\mathbf{1 9}$ & 76.033 & 60.331 & 38.843 \\
$\mathbf{9}$ & 60.331 & 60.331 & 89.256 & $\mathbf{2 0}$ & 80.165 & 70.248 & 71.901 \\
$\mathbf{1 0}$ & 81.818 & 90.083 & 97.521 & $\mathbf{2 1}$ & 90.083 & 91.736 & 95.041 \\
$\mathbf{1 1}$ & 45.455 & 57.851 & 84.298 & $\mathbf{2 2}$ & 57.851 & 45.455 & 60.331 \\
\hline
\end{tabular}

\section{ANALYSIS AND DISCUSSION}

The findings were able to quantify the characteristics of the visual landscape of the identified viewpoints in Intramuros. Through a series of correlation analysis, relationships between indicator scores and rating were analyzed.

\section{Correlation Analysis}

Table 6 shows the correlation matrix of all the indicator scores and response ratings. Imageability and Stewardship showed a strong positive relationship with beauty and interest ratings, while Disturbance showed a strong negative relationship. With this, the three indicators are given a bigger weight in computing for the visual pollution score.

The correlation matrix showed how the indicator scores and response ratings related to one another and which had the strongest weight to the visual quality, and similarly, the visual pollution of the visual landscape. A weighted average of the Image rating $(w R)$ was also calculated to better represent the respondent demographic. Responses of non-resident that have not been to Intramuros was given a weight of 1 , while all the others were assigned with the weight of 2 .

The weighted average of the scores and ratings was deemed to be representative of the visual pollution in the

Table 6. Correlation Matrix of Landscape Indicators and Response Ratings

\begin{tabular}{|c|c|c|c|c|c|c|c|c|c|}
\hline & $\mathrm{C}$ & D & $\mathbf{I}$ & $\mathbf{N}$ & VS & $S$ & BR & IR & $\operatorname{ImR}$ \\
\hline \multicolumn{10}{|l|}{ Complexity (C) } \\
\hline Disturbance (D) & 0.74 & & & & & & & & \\
\hline Imageability (I) & -0.67 & -0.48 & & & & & & & \\
\hline Naturalness (N) & -0.05 & -0.36 & -0.14 & & & & & & \\
\hline Visual Scale (VS) & 0.04 & 0.03 & -0.59 & -0.64 & & & & & \\
\hline Stewardship (S) & -0.55 & -0.45 & 0.57 & -0.16 & 0.06 & & & & \\
\hline Beauty Rating (BR) & -0.50 & -0.58 & 0.46 & 0.30 & -0.17 & 0.64 & & & \\
\hline Interest Rating (IR) & -0.51 & -0.54 & 0.60 & 0.19 & -0.03 & 0.58 & 0.88 & & \\
\hline Image Rating (ImR) & -0.52 & -0.54 & 0.80 & -0.08 & 0.13 & 0.74 & 0.67 & 0.74 & \\
\hline
\end{tabular}


landscape. The derived equation for the visual pollution score is presented below, where: VP $=$ Visual Pollution score; $\mathrm{D}=$ Disturbance percentage; $\mathrm{I}=$ Imageability percentage; $\mathrm{N}=$ Naturalness percentage; $\mathrm{V}=$ Visual Scale percentage; $\mathrm{S}=$ Stewardship percentage; and, $\mathrm{wR}=$ weighted Image percentage.

$$
V P=\frac{3 D-2 I-N-V-3 S-3 w R}{13}
$$

\section{Regression Analysis}

In order to calculate the acceptable level of visual pollution, a linear regression analysis was conducted where the independent variable, which in this case is the average visual quality, is set to 50 . The regression analysis was done on Microsoft Excel - Analysis ToolPak. This resulted to the acceptable level of VP score in Intramuros being established at -38.009 . environment to degrade and become unpleasant to its residents. The viewers are the ones capable of distinguishing whether such elements are visual pollutants or not, as it relies on shared visual preferences.

The indirect and direct methods were able to assess the visual pollution present in the landscapes of Intramuros. It was able to yield the Landscape Attribute Inventory, Response Ratings, and Interview results and insights. These series of methods were able to translate visual characteristics into measurements. Data results after analysis were able to establish the equation in calculating the visual pollution score. Through this methodology, the goal of identifying, analyzing, and measuring visual pollution in Intramuros was realized.

There are 8 of the 22 landscape codes, which subsequently consists of 14 of the 30 total viewpoints, are considered to

Table 7. Tabulation of Visual Pollution of all the landscape codes

\begin{tabular}{|c|c|c|c|c|c|c|c|}
\hline Code & D & I & $\mathbf{N}$ & V & $S$ & wR & VP \\
\hline 1 & 20.469 & 0.477 & 24.112 & 100 & 0 & 19.833 & -9.474 \\
\hline 2 & 13.980 & 6.537 & 5.876 & 55 & 60 & 72.099 & -32.947 \\
\hline 3 & 15.150 & 5.762 & 9.815 & 50 & 10 & 22.864 & -9.575 \\
\hline 4 & 0 & 57.404 & 16.601 & 100 & 100 & 97.672 & -63.417 \\
\hline 5 & 0.251 & 59.377 & 6.224 & 75 & 100 & 99.078 & -61.266 \\
\hline 6 & 3.062 & 0 & 12.819 & 100 & 60 & 36.494 & -30.240 \\
\hline 7 & 0 & 0 & 41.773 & 25 & 60 & 36.778 & -27.470 \\
\hline 8 & 11.508 & 4.534 & 16.969 & 75 & 60 & 35.555 & -27.140 \\
\hline 9 & 1.591 & 63.056 & 12.951 & 100 & 100 & 90.447 & -62.397 \\
\hline 10 & 0 & 60.986 & 26.351 & 100 & 80 & 90.447 & -58.436 \\
\hline 11 & 0.055 & 62.459 & 2.533 & 75 & 100 & 89.656 & -59.327 \\
\hline 12 & 1.435 & 45.144 & 68.371 & 25 & 100 & 82.293 & -55.864 \\
\hline 13 & 0 & 39.205 & 47.192 & 75 & 100 & 93.761 & -60.145 \\
\hline 14 & 0 & 54.105 & 33.421 & 75 & 30 & 57.355 & -36.823 \\
\hline 15 & 1.356 & 59.706 & 15.798 & 100 & 100 & 92.290 & -62.155 \\
\hline 16 & 6.703 & 39.669 & 1.960 & 75 & 100 & 95.782 & -55.567 \\
\hline 17 & 10.140 & 49.120 & 14.439 & 25 & 100 & 64.959 & -46.318 \\
\hline 18 & 0 & 23.125 & 81.069 & 0 & 80 & 66.909 & -43.696 \\
\hline 19 & 0.369 & 0.009 & 42.720 & 50 & 50 & 40.907 & -28.027 \\
\hline 20 & 1.383 & 17.313 & 50.604 & 25 & 80 & 80.822 & -45.273 \\
\hline 21 & 3.882 & 13.408 & 7.672 & 50 & 100 & 96.420 & -50.931 \\
\hline 22 & 3.286 & 12.610 & 25.70 & 58.33 & 73.33 & 71.818 & -41.135 \\
\hline
\end{tabular}

The establishment of the acceptable level of VP score identified landscape codes 1, 2, 3, 6, 7, 8, 14, and 19 as unacceptably visually polluted. Landscape code 3 Viewpoint 23 was identified as the most visually-polluted with the score of -4.886 .

\section{CONCLUSION}

This study was able to define visual pollution - and similarly, visual pollutants, as elements of the landscape that do not conform with the surrounding elements, and is unable to collaborate with the character of the built environment. These elements do not blend in with the context of the place, which causes the existing be visually-polluted. Electric posts, cable wires, and settlements that use a mishmash of indigenous materials identified as visual blight by the interviewed professionals were common elements in the unacceptably visuallypolluted viewpoints.

While the presence of the identified visual blight in landscapes may indicate a higher visual pollution score, the presence and absence of key indicators Complexity, Disturbance, Imageability, and Stewardship were able to specify which are and are not unacceptably visuallypolluted. It is also important to note that the indicators Complexity, Disturbance, and Imageability rely on the elements of the landscape and the coherence of their style 
and aesthetic with each other, which is why the presence of the identified visual blight do not automatically indicate that a viewpoint is unacceptably visually-polluted.

\section{REFERENCES}

Arriaza, M. 2004. Assessing the visual quality of rural landscapes', Landscape and Urban Planning, 69(1), pp. 115-125. doi: 10.1016/j.landurbplan.2003.10.029.

Barroga, S.D. 2020a. Datasets in 'Methodologies in the Identification, Analysis, and Measurement of Visual Pollution: The Case Study of Intramuros' [Data set]. Zenodo. doi:10.5281/zenodo.4014913

Barroga, S.D. 2020b. Interview Guide in Methodologies in the Identification, Analysis, and Measurement of Visual Pollution. Zenodo.

Barroga, S.D. 2020. Survey Questionnaire in 'Methodologies in the Identification, Analysis, and Measurement of Visual Pollution: The Case Study of Intramuros' (Version 2). Zenodo.

Chmielewski, S. et al. 2016. Measuring visual pollution by outdoor advertisements in an urban street using intervisibilty analysis and public surveys. International Journal of Geographical Information Science, 30(4). doi: 10.1080/13658816.2015.1104316.

de la Fuente de Val, G., Atauri, J.A. and de Lucio, J.V. 2006. Relationship between landscape visual attributes and spatial pattern indices: A test study in Mediterranean-climate landscapes. Landscape and Urban Planning, 77(4). doi: 10.1016/j.landurbplan.2005.05.003.

Green, R. 1999. Meaning and Form in Community Perception, Journal of Environmental Psychology, 19(4).

Jana, M. K. and De, T. 2015. Visual Pollution Can Have a Deep Degrading Effect on Urban and Sub- Urban Community: a Study in Few Places of Bengal, India, With Special Reference To Unorganized Billboards', European Scientific Journal, 7881(June).

Lynch, K. 1960. The Image of the City. Massachusetts: The M.I.T. Press. doi: 10.1177/004208168802400104.

Moles, A. 1986. The Legibility of the World: A Project of Graphic Design. Desig.n Issues, 3(1).

Ode, Å., Hagerhall, C.M. and Sang, N. 2010. Analysing visual landscape complexity: Theory and application. Landscape Research, 35(1). doi: 10.1080/01426390903414935.

Ode, Å., Tveit, M. and Fry, G. 2008. Capturing landscape visual character using indicators: Touching base with landscape aesthetic theory. Landscape Research, 33(1), pp. 89-117. doi: 10.1080/01426390701773854.

Portella, A. 2014. Visual Pollution: Advertising, Signage, and Environmental. 